ÉGYPTE

monde arabe

\section{Égypte/Monde arabe}

$3 \mid 1990$

Médiateur et métaphores 2

\title{
Crise du Golfe, annexe VI : Déclaration à l'Umma
}

Al-Ahrâm, 21 août 1990 (sous le patronage de Fahmî Huwaydî)

\section{(2) OpenEdition}

\section{Journals}

Édition électronique

URL : https://journals.openedition.org/ema/1889

DOI : $10.4000 /$ ema. 1889

ISSN : 2090-7273

Éditeur

CEDEJ - Centre d'études et de documentation économiques juridiques et sociales

Édition imprimée

Date de publication : 30 septembre 1990

Pagination : 243-246

ISSN : $1110-5097$

Référence électronique

"Crise du Golfe, annexe VI : Déclaration à l'Umma », Égypte/Monde arabe [En ligne], 3| 1990, mis en ligne le 08 juillet 2008, consulté le 07 juillet 2022. URL : http://journals.openedition.org/ema/1889 ; DOI : https://doi.org/10.4000/ema.1889

Ce document a été généré automatiquement le 7 juillet 2022

Tous droits réservés 


\title{
Crise du Golfe, annexe VI : Déclaration à l'Umma
}

\author{
Al-Ahrâm, 21 août 1990 (sous le patronage de Fahmî Huwaydî)
}

1 La conscience arabe a subi un traumatisme majeur et les bases de la sécurité ont été fortement ébranlées dans les esprits des Arabes lorsque, tous, nous avons été pris de court, le 2 août, par la nouvelle catastrophique de l'agression du régime irakien contre le Koweït, à la suite d'un différend entre les deux pays arabes frères sur des questions pétrolières, financières et frontalières, que les deux parties n'ont pas été à même de régler d'une façon pacifique, légale et reconnue sur les plans arabe et international. Puis, au moment où les complications de cette agression se sont faites de plus en plus menaçantes, ses graves conséquences sont apparues comme un véritable défi, représentant une terrible cassure dans la position arabe et un effondrement total du sentiment de sécurité dans la conscience de tous les Arabes, de l'Océan au Golfe. Ces complications ont atteint leur apogée avec la concentration militaire massive de forces dont l'importance et le nombre des parties engagées sont sans précédent. Sont arrivées des forces armées étrangères, équipées des armes les plus dangereuses et les plus destructrices, et prêtes à engager le combat au milieu de troupes arabes et islamiques, combat dirigé plus particulièrement contre l'Irak frère dont le peuple occupe dans la conscience de chaque Arabe et de chaque musulman une place due à son éminente contribution à la civilisation et à ses sacrifices au service des causes arabes.

2 Tous les ingrédients du mal le plus grave se sont réunis avec une impressionnante rapidité, d'autant que les dirigeants Arabes ont été hésitants et incapables de relever le défi, se contentant de proclamer leurs points de vue et d'échanger des insultes, d'une façon qui ne pouvait que convaincre toute conscience arabe qu'on était bien confronté là à un déclin, une incapacité plongeant profondément ses racines en terre arabe et musulmane, et ceci au moment où les Arabes et les musulmans se trouvent au seuil d'un nouveau siècle, où ils devront affronter les plus grandes menaces pour l'existence de l'Umma, du fait d'une nouvelle situation internationale où se manifeste l'hégémonie croissante de l'Occident sur notre monde arabe et islamique.

3 Face à cette situation, et alors que tous les ingrédients du plus grand mal sont réunis, différentes personnalités, ulémas, penseurs et intellectuels, s'adressent ici aux masses 
de l'Umma arabe et islamique, à ses institutions politiques, culturelles et légales, aux peuples et à leurs dirigeants, avec une invitation claire à écouter la voix de la raison, l'appel de la conscience, le sens de la responsabilité qui est le leur pour assurer la sécurité des Arabes et des musulmans, leurs intérêts et leur espoir dans l'avenir, afin qu'ils prennent - à partir de toutes ces considérations - des mesures urgentes pour circonscrire la crise et empêcher qu'elle ne se transforme en une catastrophe nationale et humaine.

4 Face à cette décadence et confrontés à ces dangers explosifs, nousadressons à l'Umma un rappel des principes et des points de vue ainsi que des mesures que nous considérons comme susceptibles de montrer la voie vers un dépassement de la crise afin d'arrêter la course vers l'abîme :

5 1. Nous croyons que la destruction, par une armée arabe musulmane, d'un État arabe musulman et son annexion - indépendamme1nt des raisons invoquées et des justifications - constituent un crime abominable qui porte une atteinte mortelle au droit des peuples à l'autodétermination et à la souveraineté sur leur territoire ainsi qu'à leur liberté de gérer leurs affaires comme ils l'entendent. De même, de tels événements représentent une violation grave des valeurs de l'Umma arabe et islamique et de ses grands principes et un reniement indéfendable de toutes les promesses, de tous les pactes et engagements sur lesquels repose le système arabe, islamique et international. La reconnaissance de tout profit qu'on pourrait tirer de ce crime est un autre crime, de même que le fait de ne pas entreprendre une action rapide pour y mettre fin constitue une soumission aux tentations du mal et à la loi de la jungle.

6 2. Cependant, si le crime de l'occupation du Koweït et du changement de son régime par la force, suivis de son annexion par l'Irak, constituent un acte des plus condamnables contre lequel il faut résister, afin d'y mettre un terme par les actes, par la conviction et par les paroles, cette résistance et cette action doivent demeurer, maintenant comme toujours, dans un cadre strictement arabe et islamique. Car la tendance interventionniste de l'étranger, et ceci d'autant plus s'il peut tacitement la déguiser comme une défense de nos droits et présenter son agression constante comme étant dans nos intérêts, tout en pratiquant deux poids deux mesures pour traiter de nos affaires et, en tout premier lieu, dans sa présentation de la question de la Palestine, cette tendance est une chose condamnable qui n'est pas moins grave ni moins dangereuse. L'accepter crée un précédent qui ouvre grand les portes à une intensification de l'intervention étrangère, ce qui ruinerait l'espoir d'édifier un système arabe indépendant, constituerait une négation de la volonté arabe et hypothéquerait gravement les intérêts arabes.

7 Nous attirons l'attention sur le fait que l'intervention étrangère visera - en premier et en dernier ressort - à la protection des intérêts étrangers, si elle ne conduit pas à l'écrasement des forces de tous les peuples arabes, dont celles du peuple frère d'Irak.

8 Insister sur les conséquences du spectre de cette odieuse intervention étrangère nous impose à tous un choix difficile, à savoir de coopérer - par une action strictement arabe et islamique - afin de mettre un terme à l'agression, d'effacer ses conséquences et d'oeuvrer à la restauration de la légalité arabe qui a été vidée et bafouée.

9 À cette fin urgente, alors que la crise est à son apogée, il faut répondre à l'agression et remédier à la faute monumentale commise par le régime irakien. Si aucune force arabe et musulmane n'a agi dans ce sens, et qu'il s'avère qu'il n'y a alors pas d'autre solution, nous insistons pour que se forme un mouvement international afin de faire cesser cet 
acte abominable, sous l'autorité des Nations-Unies ou en leur nom, et non pas sous le drapeau d'États occidentaux ou orientaux quels qu'ils soient. Ainsi s'appliquerait le principe international selon lequel, si un État ou un système régional sont incapables de répondre à une agression contre leur souveraineté et contre leur liberté, le système international représenté par les Nations-Unies est le seul recours du droit légitime dans toute intervention destinée à répondre à l'agression, amener le retour de la légalité et remettre les choses en ordre.

10 3. S'il s'avère alors qu'il est toujours impossible de parier clairement et franchement sur les origines du conflit dans nos vies arabes, et sur le responsable de la catastrophe qui est survenue... et si nous désirons, tandis que la crise approche un point de non retour, résumer les principes que nous avons énoncés, nous devons rappeler - en outre - deux fautes majeures auxquelles nous avons tous ensemble participé à différents niveaux :

1. la première faute : le silence observé sur l'oppression et sur les nombreuses atteintes aux libertés dans la vie de nos pays, ainsi que dans nos pratiques les uns envers les autres. Honorer l'être humain, respecter sa liberté et ses droits, c'est la pierre angulaire de notre civilisation arabe et islamique. Enfin, nous nous sommes de plus en plus cachés derrière des règlements de comptes par rapport à des intérêts immédiats contradictoires et à des ambitions politiques déclarées. Nous avons fermé les yeux sur ce que nous devions condamner d'atteintes abominables aux droits de l'homme et aux libertés, de violations de la dignité des individus et des minorités, et de mauvais traitements réservés aux opposants... et ceci dans les affaires les plus infimes... Nous avons oublié que l'oppression n'est pas unilatérale, et que si nous l'acceptons pour d'autres que nous, nous n'aurons pas le droit de prétendre la combattre en ce qui nous concerne.

2. la seconde faute : nous avons délaissé une autre grande valeur de notre civilisation arabe et islamique, c'est celle de lachûrâ, la consultation totalement libre entre les gens dans la gestion de leurs affaires, sous prétexte que ceux-ci sont mineurs et que l'expression individuelle au sein d'un groupe est une chose à bannir... Les dirigeants se sont hissés audessus du commun des mortels et le pouvoir personnel a été consacré - dans de nombreux pays - par une sanctification païenne qui a détruit le sentiment,de la dignité et a préparé le terrain du despotisme et de la tyrannie.

11 Les intentions agressives où se sont fourvoyés certains régimes arabes, de même que les décisions irréfléchies qu'ont en réaction hâtivement prises d'autres régimes arabes, ce qui pourrait coûter cher à des dizaines de millions d'Arabes et de musulmans, tout ceci ne serait pas arrivé s'il y avait eu entre eux un minimum dechûrâet s'il y avait des institutions véritablement responsables devant leurs peuples.

ô fils de l'Umma arabe...ô fils de l'Umma islamique... ô tous les Égyptiens... Ceci est la parole du droit, par laquelle nous condamnons l'agression irakienne contre le Koweït et proclamons notre détermination à y répondre par tous les moyens. Nous appelons à une action strictement arabe et islamique pour la circonscrire et remédier à l'acte abominable qui a été commis... comme nous attirons l'attention sur les dangers de l'intervention étrangère, dangers contre lesquels toutes les forces strictement arabes et islamiques conscientes ont mis en garde et qu'elles ont combattus pendant tant d'années... et nous faisons porter aux agresseurs aventuriers la .responsabilité historique de celle-ci comme nous attirons - enfin - l'attention sur .la nécessité d'arracher les racines de la déviation dans nos vies en respectant les libertés des individus et des peuples et la sauvegarde de leurs droits, et en leur permettant de participer, par la chûrâ, à la gestion de leurs affaires, en liquidant toutes les formes de 
l'oppression politique, sociale et économique, que ce soit dans la pratique du pouvoir ou dans la répartition des richesses. Yûsuf al-Qardâwî, Hasan 'Abbâs Zakî, D. Ahmad Haykal, Khâlid Muhammad Khâlid, D. Sultan Abu 'Alî Ahmad Bahgat, chaykh Muhammad Mustafâ Chalabî, D. Muhammad 'Imâra, D. Ne'mât Fu'âd, D. Muhammad Salîm al-'Awâ Anwar al-Gindî, D. Gamâl al-Dîn 'Atîya, D. Abd al-Hamîd al-Ghurâbî, D. Eglâl Ra'fat, D. 'Abd al Sabûr Marzûq, D. Salâh 'Abd al-Mefât, D. Laylî 'Enân, D. Hasan Châfi'î, D. sayyid Disûqî 'Adil 'Id, D. Sa'̂̂d Ismâ'il 'Alî 'Abd al-Halîm Muhammad Ahmad, D. Mahmûd Hamdî Zagzûg, Sâfînâz Kâzim, sayyid al-Qhadbân, Mahfûz 'Uzzàm, D. Hasan Ragab, Ibtisâm al Hawârî, D. Muhammad Kamâl Imam, D. Ahmad al-Mahdî, Muhammad al Mu'alîim, D. 'Abd al-Wadûd Chalabî, D. 'Awad Muhammad 'Awad, D. Hâmid al-Mawsilî, D. Ahmad Chawqî Hifnî, le conseiller 'Uthmân Husayn, D. Midhat Hasanayn, D. Bahîra Siyâm, D. Zakariyâ Matar, D. 'Abd alGhanî 'Abbûd, D. Taghrid 'Anbar, Mahgî Machhûr, Fahmî Huwaydî. 